\title{
Pharmaco-mechanical catheter-directed thrombolysis versus recanalization and stenting for post thrombotic syndrome after lower limb deep vein thrombosis: a comparative study
}

\author{
Giovanni Gautier ${ }^{1,2} \wedge$, Frederic Douane ${ }^{3}$, Arthur David ${ }^{3}$, Christophe Perret ${ }^{3}$, Marc-Antoine Pistorius $^{1}$, \\ Yann Goueffic ${ }^{4}$, Jerôme Connault ${ }^{1}$, Mathieu Artifoni ${ }^{1}$, Cecile Durant ${ }^{1}$, Gaëtan Ploton ${ }^{1}$, Alizee Raimbeau ${ }^{1}$, \\ Guillaume Bergere $^{1}$, Olivier Robin ${ }^{1}$, Blandine Maurel $^{5,6}$, Olivier Espitia ${ }^{1,6}$ \\ ${ }^{1}$ Department of Internal and Vascular Medicine, CHU de Nantes, Nantes, France; ${ }^{2}$ Department of Cardiology, Centre Hospitalier de Châteaubriant, \\ Châteaubriant, France; ${ }^{3}$ Department of Radiology, CHU de Nantes, Nantes, France; ${ }^{4}$ Department of Vascular and Endovascular Surgery, Groupe \\ Hospitalier St. Joseph, Paris, France; ${ }^{5}$ Department of Vascular Surgery, CHU de Nantes, Nantes, France; ${ }^{6}$ Université de Nantes, Nantes, France
}

Contributions: (I) Conception and design: G Gautier, O Espitia; (II) Administrative support: G Gautier, O Espitia; (III) Provision of study materials or patients: All authors; (IV) Collection and assembly of data: All authors; (V) Data analysis and interpretation: G Gautier, O Espitia; (VI) Manuscript writing: All authors; (VII) Final approval of manuscript: All authors.

Correspondence to: Dr. Olivier Espitia. Department of Internal and Vascular Medicine. CHU de Nantes, 1 Place Alexis Ricordeau, 44093 Nantes, France. Email: olivier.espitia@chu-nantes.fr.

Background: Endovenous interventional procedures can be used in addition to therapeutic anticoagulation to treat deep vein thrombosis in selected patients with proximal vein involvement (vena cava, iliac and/ or common femoral). The aim of this study was to compare venous patency and the post-thrombotic syndrome (PTS) in patients treated with pharmaco-mechanical catheter-directed thrombolysis (PMT) versus recanalization-stenting for PTS after a proximal lower limb deep vein thrombosis.

Methods: Between January 2014 and December 2020, this retrospective and monocentric study included patients with very symptomatic acute iliofemoral deep vein thrombosis treated with PMT within 21 days after diagnosis (PMT group) and patients with PTS caused by chronic venous obstruction treated with recanalization and stenting (CRS group).

Results: A total of 116 patients were included (26 PMT, 90 CRS). The rate of primary patency was $81.8 \%$ (18/22 patients) in the PMT group and 78.4\% (69/88) in the CRS group $(\mathrm{P}>0.99)$. The rate of venous patency at the last follow-up was 76.9\% (20/26) in the PMT group and 82.2\% (74/90) in the CRS group (P=0.57). The median number of stents was 2 (range, 0-5) in the PMT group and 3 (range, 0-7) in the CRS group $(\mathrm{P}<0.001)$. The median stent length was $150 \mathrm{~mm}$ (range, 60-390 mm) and $280 \mathrm{~mm}$ (range, 120-820 $\mathrm{mm}$ ), respectively $(\mathrm{P}<0.001)$. The median last Villalta score was 2 (range, $0-10)$ in the PMT group and 2 (range, 0-21) in the CRS group ( $\mathrm{P}=0.55)$. The rate of venous claudication at the last follow-up was $19.0 \%(4 / 21)$ in the PMT group and $12.0 \%(10 / 83)$ in the CRS group $(\mathrm{P}=0.47)$.

Conclusions: In this study, there was no difference in venous patency and in the rate and severity of PTS between the PMT and CRS groups. The number of stent and their length were significantly lower in the PMT group compared with the CRS group.

Keywords: Deep vein thrombosis (DVT); post-thrombotic syndrome (PTS); Villalta score; pharmaco-mechanical catheter-directed thrombolysis (PMT); venous angioplasty and stenting

^ ORCID: 0000-0001-6201-8220. 
Submitted May 29, 2021. Accepted for publication Sep 27, 2021.

doi: 10.21037/qims-21-572

View this article at: https://dx.doi.org/10.21037/qims-21-572

\section{Introduction}

Deep vein thrombosis (DVT) of the lower limb is a frequent disease with an annual incidence of $1-2$ per 1,000 people $(1,2)$. The treatment of DVT is therapeutic anticoagulation and its complications are pulmonary embolism (PE) or postthrombotic syndrome (PTS). PTS can complicate $50 \%$ of proximal DVT and $5-10 \%$ had severe PTS (3-5). PTS is caused by fibrotic remodelling of the venous wall, leading to vessel caliber narrowing and/or valve destruction. Despite anticoagulation, PTS can have a major impact on quality of life (3-5) and the cost of its management is high (6). In addition, there is debate about preventive measures for PTS. Venous compression has been challenged by the SOX study (7). Indeed, this study showed similar results on the occurrence of PTS with or without elastic compression stockings after proximal DVT. Endovenous interventional procedures can be used in addition to therapeutic anticoagulation for selected patients with proximal vein involvement (vena cava, iliac and/or common femoral). In the acute phase, pharmaco-mechanical procedures can be considered to reduce the initial symptoms and the incidence of moderate or severe PTS in the medium term $(8,9)$. In the chronic phase, recanalization by angioplasty and stenting can be discussed to treat symptomatic PTS (10-13).

The aim of this study was to compare venous patency and PTS after a proximal lower limb DVT treated either in the acute phase with Pharmaco-Mechanical catheterdirected Thrombolysis (PMT) or in the Chronic phase for venous obstruction with Recanalization and Stenting (CRS).

\section{Methods}

\section{Study population}

This retrospective study included consecutive patients from January 2014 until December 2020 in a university hospital. Comparisons were made between PMT group and CRS group consisting of patients with DVT of the lower limbs treated by endovenous procedure.

The PMT patients had a very symptomatic iliofemoral DVT associated with severe pain at rest or walking treated by PMT within 21 days after the diagnosis. The CRS patients had moderate or severe PTS according to the
Villalta scale (Villalta score $\geq 10$ ) or/and venous claudication with sequelae of the common femoral, iliac or inferior vena cava treated by recanalization-stenting.

The first phase of the endovenous procedure in PMT group was the delivery of plasminogen activator during 30 minutes, directly into lower limbs clot and the second phase was thrombectomy with the use of the Angiojet ${ }^{\circledR}$ (Boston Scientific) or PTD ${ }^{\circledR}$ system (Arrow-Trerotola). Stenting was performed for obstructive lesions causing $\geq 50 \%$ diameter narrowing in the inferior vena cava, iliac vein or common femoral vein.

The first phase of the endovenous procedure in CRS group was an angioplasty with balloons. Then, stents were placed in the sequelae veins to a landing zone below in a stenosis-free location.

Procedure failure meant obstructive thrombosis causing $\geq 50 \%$ diameter narrowing or complete occlusion in the vein and/or stent at the end of the procedure.

In the immediate postoperative period after both procedures, intermittent pneumatic compression was applied during hospitalization. After discharge, venous compression stockings were systematic. Post-procedure treatment included anti-platelet therapies for one month combined with therapeutic anticoagulation consisting of two periods: a three-week period with rivaroxaban $15 \mathrm{mg}$ twice daily or tinzaparin $175 \mathrm{U} / \mathrm{kg} /$ day followed by therapeutic anticoagulation with rivaroxaban $20 \mathrm{mg}$ once daily or vitamin $\mathrm{K}$ antagonist (VKA) therapy with an international normalized ratio (INR) target of 2 to 3 .

\section{Follow-up}

The data were collected using a standardized grid. We collected both data before procedure (patient and venous thrombosis characteristics); types of procedure and data after the procedure (complications, venous and stent patency and clinical evaluation).

Clinical evaluation and systematic Duplex ultrasound were performed 1 day after the procedure and at 1 month, 3 months, 6 months, 1 year and once a year. Most of the patients with ilio-femoral stent had computed tomography (CT) at 1,2 and 5 years after stenting and after inferior vena cava stenting another $C T$ was performed at 6 months. 
For venous patency data: primary patency was defined as anterograde flow with $<50 \%$ stenosis on follow-up without any repeat endovenous procedure. Patency at the last follow-up defined as anterograde flow with $<50 \%$ stenosis at the last follow-up with or without initial technical success or/and repeat endovenous procedure $(10,14)$.

In case of thrombosis occurring within 14 days after stenting, pharmaco-mechanical thrombolysis was performed with flow assessment and if necessary, a new angioplastystenting.

In case of symptomatic stenosis or $>50 \%$ stenosis, angioplasty with or without stenting was performed. In case of endovascular intervention failed, nor bypass either other surgery was performed.

For clinical evaluation: PTS defined as a Villalta score $\geq 5$ at the last follow-up. Scores $<5$ indicate absence of PTS, a score of 5-9 indicates mild PTS, 10-14 indicates moderate PTS, and a Villalta score $>15$ indicates severe PTS (15).

The primary endpoint of the study was to compare venous patency between PMT and CRS. The secondary endpoints of the study were to compare procedure data; to compare procedure-related complications; to compare PTS; to compare clinical characteristics before and after procedure and to compare antiplatelet and anticoagulant therapy before and after procedure between PMT and CRS.

\section{Ethical statement}

This study has been conducted in compliance with the Declaration of Helsinki principles (as revised in 2013) and has received ethics board approval by GNEDS (Groupe Nantais d'Ethique et de Soins), the local ethics committee of the University Hospital of Nantes (GNEDS-20190606), and complied with the requirements of the "Commission Nationale de l'Informatique et des Libertés", in accordance with current French legislation. Informed consent was waived due to the retrospective nature of the medical record review.

\section{Statistical analysis}

The data were compared with the Fisher's exact test or a Chi-square test based on the number of patients to compare categorical variables and the Student's $t$-test to compare normally distributed continuous variables between groups. Cumulative probabilities of primary patency, patency at the last follow-up, continued anticoagulation, the occurrence of PTS and moderate to severe PTS were calculated using Kaplan-Meier method and the log-rank test was used for comparison curved. $\mathrm{P}$ value $<0.05$ was considered significant. GraphPad software was used to perform analyses (San Diego, USA).

\section{Results}

\section{Clinical characteristics and location of venous damage}

This study included 116 patients, $58.6 \%(\mathrm{n}=68)$ were female with a median age of 42.5 years (range, $14-82$ years) and a median follow-up of 27 months (range, 0-69 months).

Characteristics of patients and deep-vein thrombosis risk factors are summarized in Table 1.

Active cancers were more frequent in PMT group. Cancers diagnosed in the PMT group were ovarian, breast, lung with brain metastases and cervical. A left iliac vein leiomyosarcoma and a recurrence of ovarian cancer were diagnosed after DVT in the CRS group. Table 2 shows, at the time of procedure, the extent of venous damage with the locations of vein thrombosis for PMT group and parietal venous sequelae for CRS group.

\section{Stenting data}

Endovenous procedure data are described in Table 3. Mean number of stents for each procedure was 2.0 [standard deviation $(\mathrm{SD}) \pm 1.1]$ in the PMT group and $3.1(\mathrm{SD} \pm 1.5)$ in the CRS group $(\mathrm{P}<0.001)$.

\section{Procedure-related complications}

Regarding procedure complications, there were in the PMT group one arteriovenous fistula (AVF), one combined $\mathrm{AVF}$ and false aneurysm, one psoas hematoma, one renal insufficiency secondary to rhabdomyolysis due to prolonged prone decubitus in obese patient and 5 symptomatic PE with one was fatal PE. In PMT group, five procedures were complicated by symptomatic PE. In these cases, four had vena cava thrombosis initially, 2 of which had PE despite the placement of a cava filter at the beginning of the procedure.

There were $19.2 \% \mathrm{PE}$ in the PMT group $v$ s. none in the CRS group $(\mathrm{P}<0.001)$. In the CRS group, there were $2 \mathrm{AVF}$, one patient had immediate hematoma at the puncture site, one thigh hematoma and two hematuria.

\section{Venous patency}

Cumulative rates of primary venous patency, venous patency 
Table 1 Characteristics of patients and deep-vein thrombosis risk factors

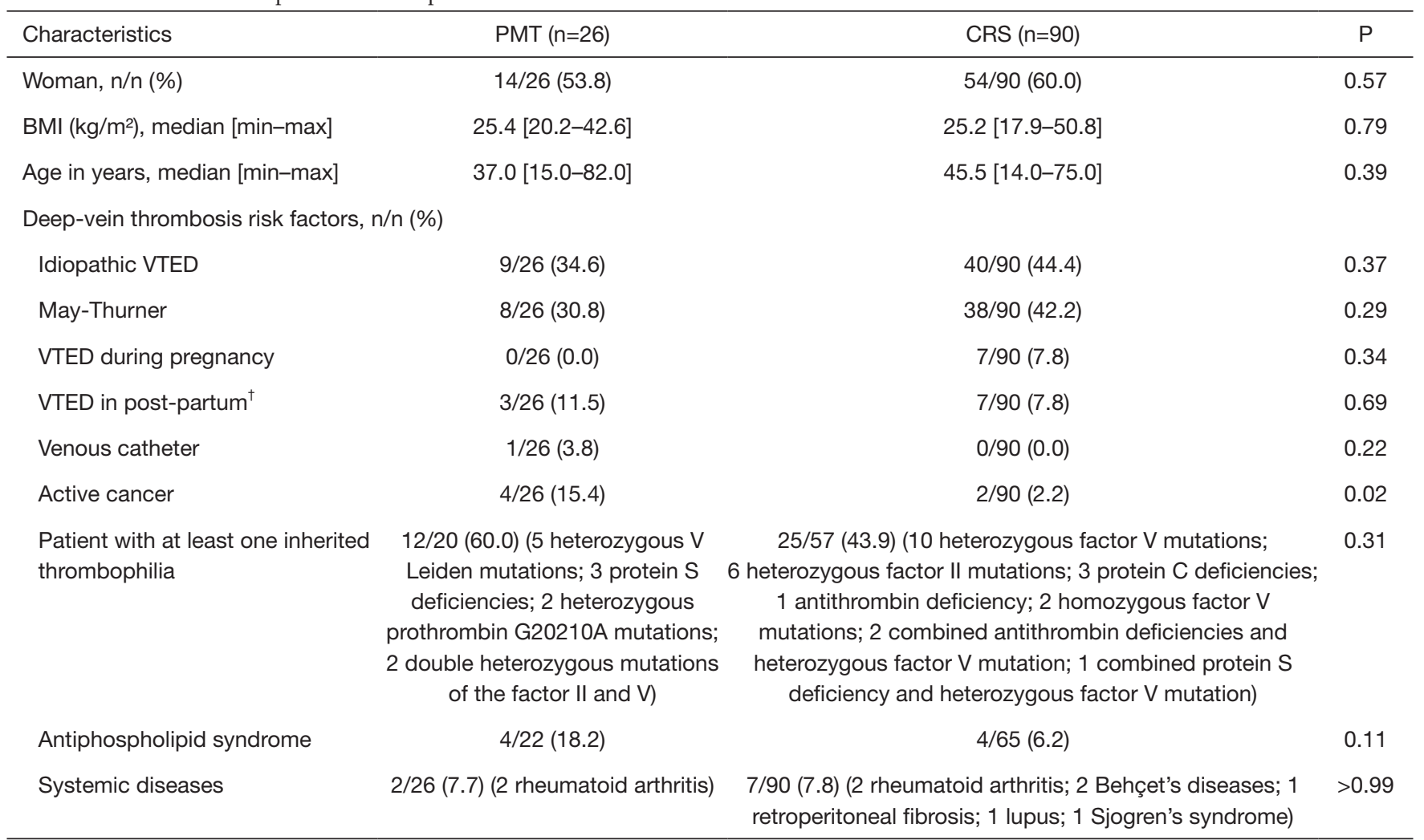

${ }^{\dagger}$, during 3 months after delivery. BMI, body mass index; VTED, venous thrombo-embolic disease; PMT, pharmaco-mechanical catheterdirected thrombolysis; CRS, chronic venous obstruction treated with recanalization-stenting.

Table 2 Location of vein lesions at the time of procedure; vein thrombosis in PMT group and parietal venous sequelae in CRS group

\begin{tabular}{|c|c|c|c|}
\hline Location & PMT (n=26), n/n (\%) & CRS (n=90), n/n (\%) & $\mathrm{P}$ \\
\hline Bilatéral & 6/26 (23.1) & 22/90 (24.4) & 0.88 \\
\hline Inferior vena cava & $10 / 26(38.5)$ & $24 / 90(26.7)$ & 0.24 \\
\hline Iliac and/or common femoral vein & 26/26 (100.0) & $90 / 90(100.0)$ & $>0.99$ \\
\hline Femoral vein & 25/26 (96.2) & $42 / 90(46.7)$ & $<0.001$ \\
\hline Deep femoral vein & 20/26 (76.9) & $19 / 90(21.1)$ & $<0.001$ \\
\hline Popliteal and/or subpopliteal veins & $17 / 26(65.4)$ & $7 / 90(7.8)$ & $<0.001$ \\
\hline
\end{tabular}

PMT, pharmaco-mechanical catheter-directed thrombolysis; CRS, chronic venous obstruction treated with recanalization-stenting.

at the last follow-up and anticoagulant therapy at the last follow-up are shown in Figure 1. The rate of primary patency was $81.8 \%$ (18/22 patients) in the PMT group and $78.4 \%(69 / 88)$ in the CRS group $(\mathrm{P}>0.99)$. The rate of venous patency at the last follow-up was $76.9 \%(20 / 26)$ in the PMT group and $82.2 \%(74 / 90)$ in the CRS group $(\mathrm{P}=0.57)$.

Two patients in the PMT group had second procedure 
Table 3 Data on venous interventional procedures and venous stent locations

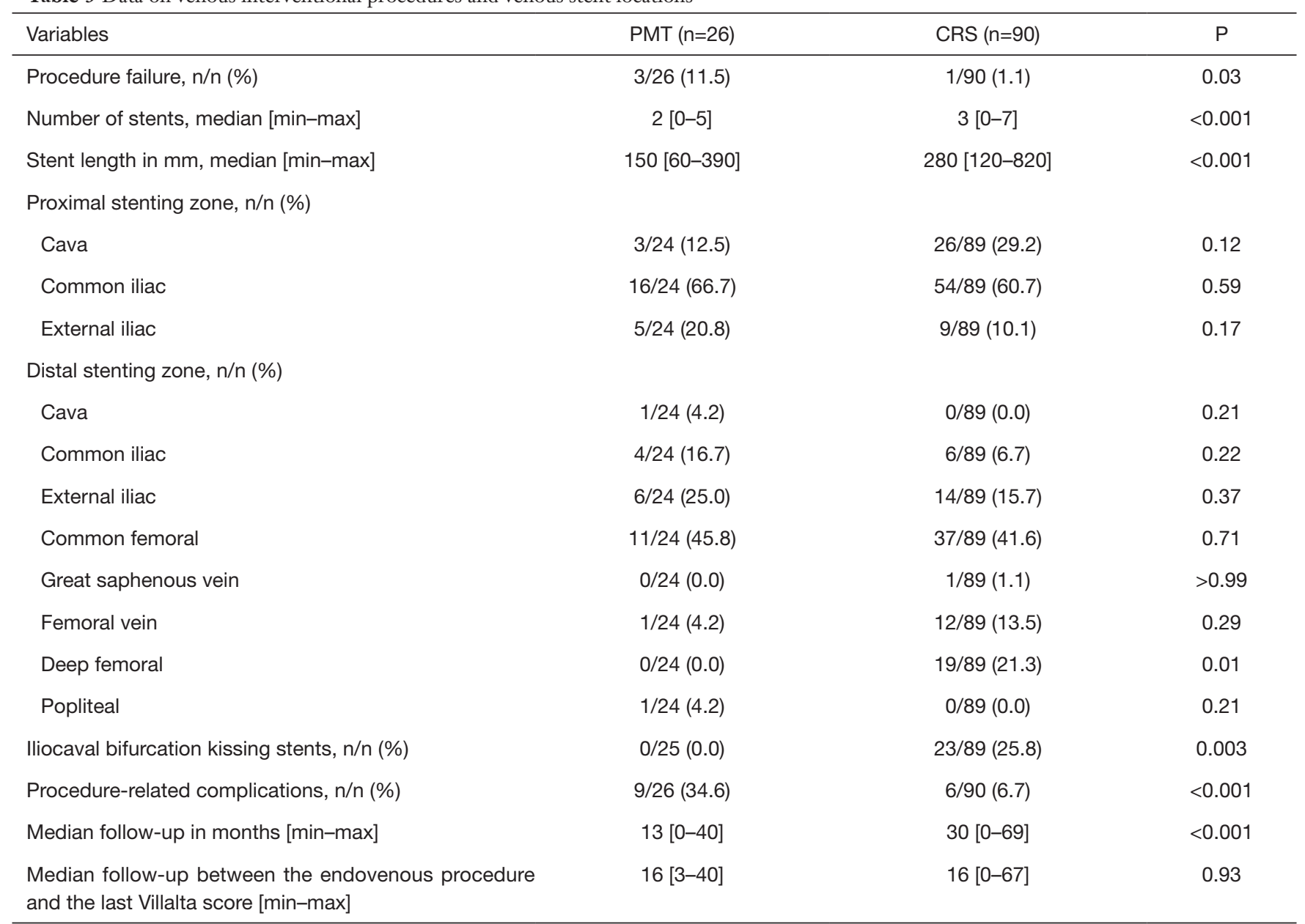

PMT, pharmaco-mechanical catheter-directed thrombolysis; CRS, chronic venous obstruction treated with recanalization-stenting.

after stent thrombosis with one being successful and the other failing. Sixteen patients had second procedure in the CRS group with fifteen successes and one failure. None stent fracture was described in the PMT group vs. 5 in the CRS group $(\mathrm{P}=0.58)$.

\section{Anticoagulant treatment}

After procedure, most of the patients had 3 weeks of rivaroxaban $30 \mathrm{mg} /$ day then $20 \mathrm{mg} /$ day or 4 weeks of tinzaparin $175 \mathrm{U} / \mathrm{kg} /$ day then $\mathrm{VKA}$ or direct oral anticoagulant (DOAC). The therapeutic anticoagulation regimen was the same after procedure for the patients managed in the PMT or in the CRS group. Initial therapeutic anticoagulation after procedure in the PMT and CRS group were $69.2 \%(18 / 26)$ of DOACs $v s$.
$73.3 \%(66 / 90)$ respectively $(\mathrm{P}=0.68), 19.2 \%(5 / 26)$ of low molecular weight heparins (LMWHs) vs. 24.4\% (22/90) respectively $(\mathrm{P}=0.79)$ and $11.5 \%(3 / 26)$ of unfractionated heparin (UFH) vs. none respectively $(\mathrm{P}=0.01)$. In the CRS group, one patient continued on VKA without switching and one patient received clopidogrel only. In the PMT group initially treated with heparin (LMWH or UFH), $14.3 \%(1 / 7)$ of patients were switched to VKAs, $42.9 \%(3 / 7)$ were switched to DOACs and $42.9 \%$ (3/7) remained on LMWH in the context of cancer. In the CRS group initially treated with LMWH, $54.5 \%$ of patients $(12 / 22)$ were switched to VKAs, $36.4 \%(8 / 22)$ to DOACs, one patient remained on $\mathrm{LMWH}$ without switching due to pregnancy and one patient was lost to follow-up. In the PMT group, $73.1 \%(19 / 26)$ of patients received at least one month of antiplatelet therapy compared to $94.4 \%(84 / 89)$ in the 

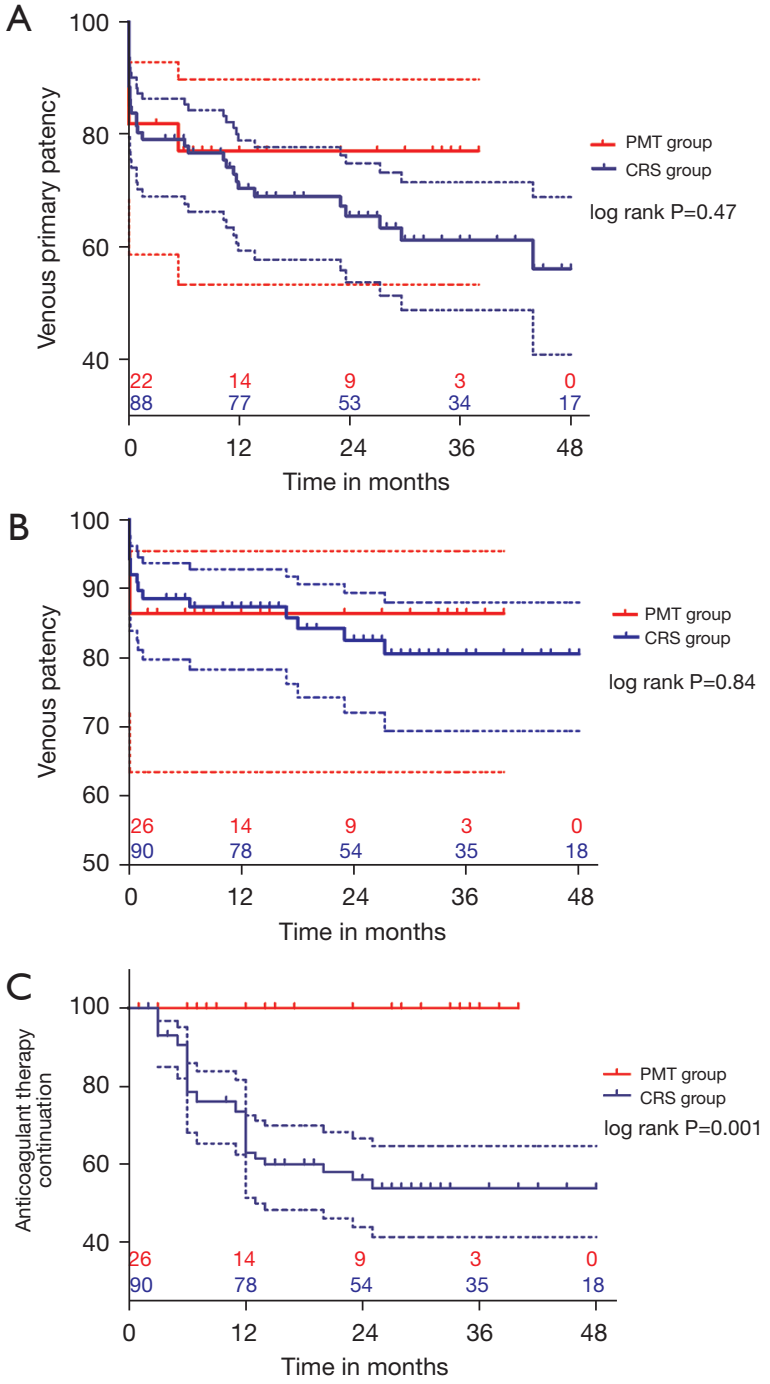

Figure 1 Kaplan-Meier survival curves of venous patency and for continuation of anticoagulant therapy. Numbers of patients at risk at given time intervals. Solid central lines are the KaplanMeier survival curves. The dashed lines represent the $95 \%$ confidence interval. (A) Kaplan-Meier survival curves of primary venous patency; (B) Kaplan-Meier survival curves of primary and secondary venous patency; (C) Kaplan-Meier survival curves for continuation of anticoagulant therapy. PMT, pharmaco-mechanical catheter-directed thrombolysis; CRS, chronic venous obstruction treated with recanalization-stenting.

CRS group $(\mathrm{P}=0.005)$. All patients in the PMT group had therapeutic anticoagulation at the last follow-up vs. $71.1 \%$ (64/90) in the CRS group $(\mathrm{P}<0.001)$. In patients continuing anticoagulation, 7/26 patients in the PMT group switched to half-dose of DOACs vs. 10/64 patients in the CRS
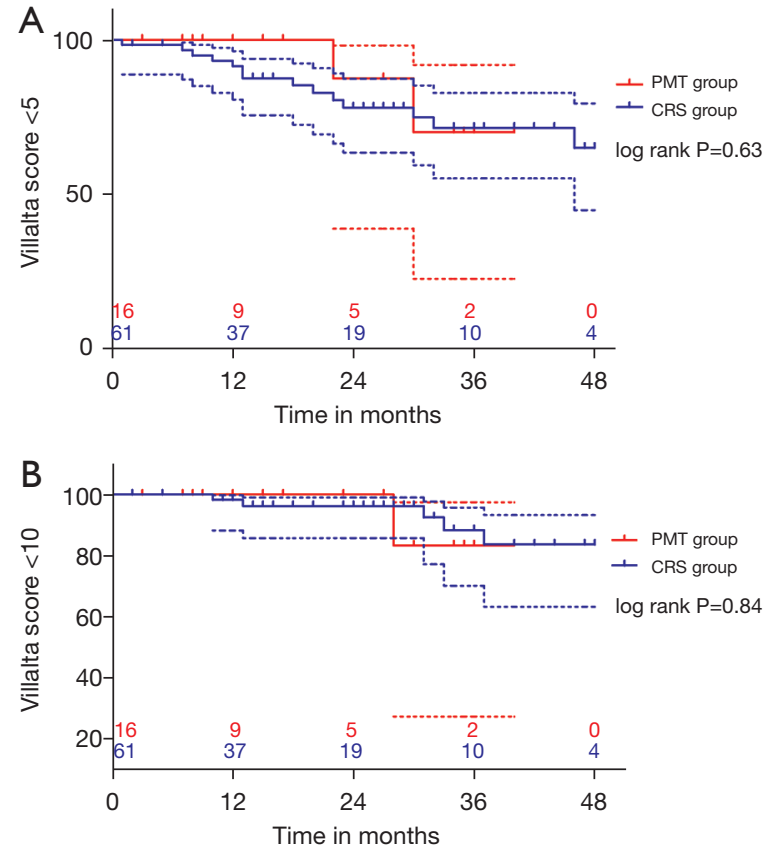

Figure 2 Kaplan-Meier survival curves of Villalta score. Numbers of patients at risk at given time intervals. Solid central lines are the Kaplan-Meier survival curves. The dashed lines represent the 95\% confidence interval. (A) Kaplan-Meier survival curves of Villalta score $<5$; (B) Kaplan-Meier survival curves of Villalta score $<10$. PMT, pharmaco-mechanical catheter-directed thrombolysis; CRS, chronic venous obstruction treated with recanalization-stenting.

group (26.9\% vs. $15.6 \% ; \mathrm{P}=0.24)$. The mean duration of anticoagulation was $17.0(\mathrm{SD} \pm 13.4)$ months in the PMT group and $17.9(\mathrm{SD} \pm 14.9)$ months in the CRS group $(\mathrm{P}=0.75)$.

\section{PTS}

The cumulative rates of Villalta score $<5$ and $<10$ at the last follow-up are shown in Figure 2. The median last Villalta score was 2 (range, $0-10$ ) in the PMT group and 2 (range, 0-21) in the CRS group. The mean last Villalta score was 2.3 $(\mathrm{SD} \pm 2.7)$ in the PMT group and $3.2(\mathrm{SD} \pm 4.1)$ in the CRS group $(\mathrm{P}=0.55)$. The rate of venous claudication at the last follow-up was $19.0 \%(4 / 21)$ in the PMT group and $12.0 \%$ $(10 / 83)$ in the CRS group $(\mathrm{P}=0.47)$.

\section{Discussion}

To our knowledge, this study is the largest comparing pharmaco-mechanical thrombolysis for the treatment of 
acute DVT and recanalization-stenting for the treatment for chronic venous obstruction after lower limbs DVT.

In this study, there was no difference in venous patency, our primary endpoint, between the PMT and CRS groups. The rates of PTS were not different between the 2 groups. It also demonstrated that during PMT, fewer stents were implanted. Best anticoagulant treatment strategy after venous stenting is actually not known; and depend on numerous risk factors. Medical follow-up after the procedure to detect medium-term complications seems important for these patients.

\section{Venous patency}

In this study, there was no difference in venous patency between the PMT and CRS groups. The primary patency rate was $81.8 \%$ in our PMT group, this rate is described to vary from $64 \%$ to $96 \%$ (16-21). For recanalization-stenting in chronic obstructions, the primary patency rate in this study was $78.4 \%$ and it ranged from $59 \%$ to $85 \%$ in others studies (10-12,14,21-24).

Nevertheless, the procedure failure rate was significantly different; it was higher in the PMT group. In acute phase of DVT, local inflammation of the venous wall and systemic inflammation are additional thrombosis factors. Furthermore, in acute phase, patients are painful and decrease their walking time which further reduces venous flow. Acute thrombolysis studies reported procedure failure rates ranging from $4 \%$ to $14 \%(14-16,19)$. In recanalization-stenting for chronic obstruction, there is no systemic or parietal inflammation, only fibrous bands in the venous lumen. Thus, in these procedures, there is no more thrombus, which reduces the risk of embolization. The procedure failure rates ranged from 0 to $4 \%$ in studies on recanalization-stenting for chronic obstruction $(10,14,24)$.

\section{Stenting data}

In the PMT group, the length and number of stents were lower than in the CRS group due to a less pathological venous wall. Indeed, in the acute phase, there is less wall synechia that require the placement of a stent. In acute procedure, stent is only inserted in the areas of compression/stenosis. In the acute phase of DVT, the distal vein wall below the obstacle does not have time to deteriorate, remodel and progress to fibrosis. This is in opposition to chronically occluded veins which became fibrous and require more stents to restore sufficient lumen and correct flow. In the literature, there were also fewer stents placed in acute thrombolysis with a mean of 1.1 stent placed in 2 studies $(19,20)$ compared to a mean of 3.4 and median of 3 in studies of recanalization-stenting in chronic venous obstruction $(10,14,24)$.

\section{Procedure-related complications}

There were 5 symptomatic PE following the procedure in our PMT group, one of them resulted in death, and none in the CRS group. This significant difference was explained by the presence of recent thrombus in proximal veins which was fragmented by thrombolysis and sometimes not aspirated by the device. This clot was able to embolise in pulmonary arteries despite the presence of a cava filter. In the literature, it is often difficult to distinguish between procedure-related $\mathrm{PE}$ and $\mathrm{PE}$ occurring during follow-up and not related to the procedure. However, it seems that $\mathrm{PE}$ are less frequent in studies of acute thrombolysis with rates of $0-5 \%(16-18,20)$ compared to our results. This difference could be explained by a systematic screening for signs of $\mathrm{PE}$ after each procedure in our study. On the other hand, as in our study, no PE was reported in several studies of recanalization-stenting in chronic obstruction $(11,14,23,24)$.

\section{Post thrombotic syndrome}

There was no difference in the rate and severity of PTS; the median last Villalta score was 2 in both groups. In this venous interventional study, Villalta scores were very low corresponding to the absence of PTS. In literature, the mean Villalta score ranged from 3.1 to 4 at 12 months in acute thrombolysis studies $(9,18)$. For recanalizationstenting in chronic venous obstructions, the median Villalta score was from 3 to 5 at 3 or 6 months $(14,24)$.

\section{Clinical characteristics}

There were significantly more cancers in the PMT group which added a deep-vein thrombosis risk factor. In the literature $3 \%$ to $36 \%$ cancers were found after acute procedure $(16,17,25-27)$ and for recanalization-stenting in chronic obstruction, the rate of cancer context ranged from 0 to $6 \%$ without specifying the disease activity at the time of recanalization $(10,12,28)$. The small interval between diagnosis of DVT and acute procedure may explain this higher frequency since there is a limited time to perform 
oncological explorations. Recanalization-stenting in chronic obstruction is offered after a period of several months. This allows oncologic screening and clinical evaluation of patients to identify asymptomatic cancer.

\section{Anticoagulation after procedure}

The number of patients with therapeutic anticoagulation at the last follow-up was significantly lower in the CRS group compared with the PMT group. One reason may be that patients in the CRS group, DVT and procedure were performed 6 months apart which allowed time for rigorous etiologic and thrombophilia explorations and allowed a better assessment of anticoagulation duration. However, interruption of anticoagulation treatment after acute thrombolysis appeared to be more frequent in the literature. In some studies, the rate of interruption ranged from $20 \%$ to $39 \%$ at 6 months and from $34 \%$ to $45 \%$ at 24 months $(9,16)$. The maintenance of anticoagulation for our PMT patients could be explained by the lack of knowledge of risk factors for recurrence of DVT in patients with lower extremity venous stents and consideration of the wish of several patients to continue anticoagulation because of very symptomatic DVT with a major handicap initially. However, in order to limit the risk of bleeding, some patients had a half-dose reduction of anticoagulation by DOACs. This dose reduction was offered after a 1-year follow-up with perfect stent patency.

\section{Limitations}

This study has several limitations, it was retrospective and monocentric with limited follow-up time, Villalta score was not available for all patients. Moreover, the CRS venous lesion staging for patency prognosis, described by Menez et al. (24), was not available. Anticoagulation and antiplatelet regimens were not standardized for either type or duration of treatment, but most of the patients had a 4 weeks antiplatelet drug with therapeutic anticoagulant treatment. However, to our knowledge, it was the largest study to compare PMT for acute DVT and recanalization-stenting for chronic venous obstruction. Prospective and multicenter study is needed to confirm these results.

\section{Conclusions}

This study showed no difference in primary venous patency and at the last follow-up between PMT group and CRS group. Also, it showed no difference in the rate of PTS with a low Villalta score in the 2 groups. Nevertheless, the study showed more procedure-related complications in the PMT group, including more PE. However, stents placed in the PMT group were fewer and shorter but the impact on venous patency at long-term follow-up is not known. Thus, prospective studies with larger patient samples and longer follow-ups are required to compare PTS and to evaluate cost-effectiveness of vein interventional procedure after lower limbs DVT.

\section{Acknowledgments}

Funding: Dr. Olivier Espitia received a mobility grant from French Society of Vascular Medicine (SFMV).

\section{Footnote}

Conflicts of Interest: All authors have completed the ICMJE uniform disclosure form (available at https://dx.doi. org/10.21037/qims-21-572). FD reports research funding from Cook medical, Optimed, WL Gore and personal fees and grants from Cook medical, Optimed, WL Gore (medical advisory board, educational course, speaking). YG reports research funding from Abbott, General Electric, Veryan, WL Gore and personal fees and grants from Abbott, Bard, Biotronik, Boston Scientic, Cook, General Electric, Medtronic, Penumbra, Terumo, Veryan, WL Gore (medical advisory board, educational course, speaking). BM reports consulting and proctoring fees from COOK medical and consulting fees from Philips Medical. OE reports research funding from Boston Scientific (Industry-Sponsored Research). The other authors have no conflicts of interest to declare.

Ethical Statement: The authors are accountable for all aspects of the work in ensuring that questions related to the accuracy or integrity of any part of the work are appropriately investigated and resolved. This study has been conducted in compliance with the Declaration of Helsinki principles (as revised in 2013) and has received ethics board approval by GNEDS (Groupe Nantais d'Ethique et de Soins), the local ethics committee of the University Hospital of Nantes (GNEDS-20190606), and complied with the requirements of the "Commission Nationale de l'Informatique et des Libertés", in accordance with current French legislation. Informed consent was waived due to the retrospective nature of the medical record review. 
Open Access Statement: This is an Open Access article distributed in accordance with the Creative Commons Attribution-NonCommercial-NoDerivs 4.0 International License (CC BY-NC-ND 4.0), which permits the noncommercial replication and distribution of the article with the strict proviso that no changes or edits are made and the original work is properly cited (including links to both the formal publication through the relevant DOI and the license). See: https://creativecommons.org/licenses/by-nc-nd/4.0/.

\section{References}

1. Delluc A, Tromeur C, Le Ven F, Gouillou M, Paleiron N, Bressollette L, Nonent M, Salaun PY, Lacut K, Leroyer C, Le Gal G, Couturaud F, Mottier D; EPIGETBO study group. Current incidence of venous thromboembolism and comparison with 1998: a community-based study in Western France. Thromb Haemost 2016;116:967-74.

2. Naess IA, Christiansen SC, Romundstad P, Cannegieter SC, Rosendaal FR, Hammerstrøm J. Incidence and mortality of venous thrombosis: a population-based study. J Thromb Haemost 2007;5:692-9.

3. Ikesaka RT, Kahn SR, Galanaud JP, Vazquez FJ, RocheNagle G, Carrier M, Le Gal G, Rodger M, Gandara E. The importance of post thrombotic syndrome as an outcome after deep venous thrombosis: A survey of Canadian thrombosis clinicians. Thromb Res 2017;159:13-5.

4. Galanaud JP, Monreal M, Kahn SR. Epidemiology of the post-thrombotic syndrome. Thromb Res 2018;164:100-9.

5. Wik HS, Enden TR, Ghanima W, Engeseth M, Kahn SR, Sandset PM. Diagnostic scales for the post-thrombotic syndrome. Thromb Res 2018;164:110-5.

6. Guanella R, Ducruet T, Johri M, Miron MJ, Roussin A, Desmarais S, Joyal F, Kassis J, Solymoss S, Ginsberg JS, Lamping DL, Shrier I, Kahn SR. Economic burden and cost determinants of deep vein thrombosis during 2 years following diagnosis: a prospective evaluation. J Thromb Haemost 2011;9:2397-405.

7. Kahn SR, Shapiro S, Wells PS, Rodger MA, Kovacs MJ, Anderson DR,, et al. Compression stockings to prevent post-thrombotic syndrome: a randomised placebocontrolled trial. Lancet 2014;383:880-8.

8. Vedantham S, Goldhaber SZ, Julian JA, Kahn SR, Jaff MR, Cohen DJ,, et al. Pharmacomechanical Catheter-Directed Thrombolysis for Deep-Vein Thrombosis. N Engl J Med 2017;377:2240-52.

9. Comerota AJ, Kearon C, Gu CS, Julian JA, Goldhaber
SZ, Kahn SR, Jaff MR, Razavi MK, Kindzelski AL, Bashir R, Patel P, Sharafuddin M, Sichlau MJ, Saad WE, Assi Z, Hofmann LV, Kennedy M, Vedantham S; ATTRACT Trial Investigators. Endovascular Thrombus Removal for Acute Iliofemoral Deep Vein Thrombosis. Circulation 2019;139:1162-73.

10. Falcoz MT, Falvo N, Aho-Glélé S, Demaistre E, Galland C, Favelier S, Pottecher P, Chevallier O, Bonnotte B, Audia S, Samson M, Terriat B, Midulla M, Loffroy R; Study Group on Treatment of Venous Diseases. Endovascular stent placement for chronic post-thrombotic symptomatic ilio-femoral venous obstructive lesions: a single-center study of safety, efficacy and quality-of-life improvement. Quant Imaging Med Surg 2016;6:342-52.

11. Erben Y, Bjarnason H, Oladottir GL, McBane RD, Gloviczki P. Endovascular recanalization for nonmalignant obstruction of the inferior vena cava. J Vasc Surg Venous Lymphat Disord 2018;6:173-82.

12. Black S, Gwozdz A, Karunanithy N, Silickas J, Breen K, Hunt B, Smith A, Cohen A, Saha P. Two Year Outcome After Chronic Iliac Vein Occlusion Recanalisation Using the Vici Venous Stent ${ }^{\circledR}$. Eur J Vasc Endovasc Surg 2018;56:710-8.

13. Mahnken AH, Thomson K, de Haan M, O'Sullivan GJ. CIRSE standards of practice guidelines on iliocaval stenting. Cardiovasc Intervent Radiol 2014;37:889-97.

14. Guillen K, Falvo N, Nakai M, Chevallier O, Aho-Glélé S, Galland C, Demaistre E, Pescatori L, Samson M, Audia S, Bonnotte B, Midulla M, Loffroy R. Endovascular stenting for chronic femoro-iliac venous obstructive disease: Clinical efficacy and short-term outcomes. Diagn Interv Imaging 2020;101:15-23.

15. Strijkers RH, Wittens $\mathrm{CH}$, Kahn SR. Villalta scale: goals and limitations. Phlebology 2012;27 Suppl 1:130-5.

16. Enden T, Haig Y, Kløw NE, Slagsvold CE, Sandvik L, Ghanima W, Hafsahl G, Holme PA, Holmen LO, Njaastad AM, Sandbæk G, Sandset PM; CaVenT Study Group. Long-term outcome after additional catheterdirected thrombolysis versus standard treatment for acute iliofemoral deep vein thrombosis (the CaVenT study): a randomised controlled trial. Lancet 2012;379:31-8.

17. Gombert A, Gombert R, Barbati ME, Bruners P, Keszei A, Wittens C, Jalaie H, Grommes J. Patency rate and quality of life after ultrasound-accelerated catheter-directed thrombolysis for deep vein thrombosis. Phlebology 2018;33:251-60.

18. Rabuffi P, Vagnarelli S, Bruni A, Gallucci M, Ambrogi C, Passaro G, Flore RA, Tondi P. Pharmacomechanical 
catheter-directed thrombolysis for acute iliofemoral deep vein thrombosis: our case series. Eur Rev Med Pharmacol Sci 2019;23:2244-52.

19. Park JY, Ahn JH, Jeon YS, Cho SG, Kim JY, Hong KC. Iliac vein stenting as a durable option for residual stenosis after catheter-directed thrombolysis and angioplasty of iliofemoral deep vein thrombosis secondary to MayThurner syndrome. Phlebology 2014;29:461-70.

20. Xue GH, Huang XZ, Ye M, Liang W, Zhang H, Zhang JW, Zhang BG. Catheter-directed thrombolysis and stenting in the treatment of iliac vein compression syndrome with acute iliofemoral deep vein thrombosis: outcome and follow-up. Ann Vasc Surg 2014;28:957-63.

21. Attaran RR, Ozdemir D, Lin IH, Mena-Hurtado C, Lansky A. Evaluation of anticoagulant and antiplatelet therapy after iliocaval stenting: Factors associated with stent occlusion. J Vasc Surg Venous Lymphat Disord 2019;7:527-34.

22. van Vuuren TM, Doganci S, Toonder IM, Graaf R, Wittens CH. Venous stent patency may be affected by collateral vein lumen size. Phlebology 2019;34:32-9.

23. Qiu P, Zha B, Xu A, Wang W, Zhan Y, Zhu X, Yuan X. Systematic Review and Meta-Analysis of Iliofemoral Stenting for Post-thrombotic Syndrome. Eur J Vasc Endovasc Surg 2019;57:407-16.

Cite this article as: Gautier G, Douane F, David A, Perret C, Pistorius MA, Goueffic Y, Connault J, Artifoni M, Durant C, Ploton G, Raimbeau A, Bergere G, Robin O, Maurel B, Espitia O. Pharmaco-mechanical catheter-directed thrombolysis versus recanalization and stenting for post thrombotic syndrome after lower limb deep vein thrombosis: a comparative study. Quant Imaging Med Surg 2022;12(3):1664-1673. doi: 10.21037/qims-21-572
24. Menez C, Rodiere M, Ghelfi J, Seinturier C, Martinelli T, Imbert B, Perolat R, Bouzat P, Blaise S, Carpentier P, Pernod G, Thony F. Endovascular Treatment of Postthrombotic Venous Ilio-Femoral Occlusions: Prognostic Value of Venous Lesions Caudal to the Common Femoral Vein. Cardiovasc Intervent Radiol 2019;42:1117-27.

25. Madsen CP, Gesla J, Vijdea RL, Serifi MA, Christensen

JK, Houlind K. Results of catheter-directed thrombolysis for acute ilio-femoral deep venous thrombosis - A retrospective cohort study. JRSM Cardiovasc Dis 2018;7:2048004018766801.

26. Lindsey P, Echeverria A, Poi MJ, Matos J, Bechara CF, Cheung M, Lin PH. Thromboembolic Risk of Endovascular Intervention for Lower Extremity Deep Venous Thrombosis. Ann Vasc Surg 2018;49:247-54.

27. Liu B, Liu M, Yan L, Yan J, Wu J, Jiao X, Guo M.

Percutaneous mechanical thrombectomy combined with catheter-directed thrombolysis in the treatment of acute pulmonary embolism and lower extremity deep venous thrombosis: A novel one-stop endovascular strategy. J Int Med Res 2018;46:836-51.

28. Murphy EH, Johns B, Varney E, Raju S. Endovascular management of chronic total occlusions of the inferior vena cava and iliac veins. J Vasc Surg Venous Lymphat Disord 2017;5:47-59. 